\title{
Overweight and obesity knowledge prior to pregnancy: a survey study
}

\author{
Marloes Dekker Nitert ${ }^{1}$, Katie F Foxcroft ${ }^{2}$, Karin Lust ${ }^{3}$, Narelle Fagermo ${ }^{3}$, Debbie A Lawlor ${ }^{4}$, Michael O'Callaghan ${ }^{5}$,
} H David Mcintyre, ${ }^{6,7}$ and Leonie K Callaway ${ }^{7,8^{*}}$

\begin{abstract}
Background: Overweight and obesity are associated with increased risk for pregnancy complications. Knowledge about increased risks in overweight and obese women could contribute to successful prevention strategies and the aim of this study is to assess current levels of knowledge in a pregnant population.

Methods: Cross sectional survey of 412 consecutive unselected women in early pregnancy in Brisbane, Australia: 255 public women attending their first antenatal clinic visit and 157 women at private maternal fetal medicine clinics undergoing a routine ultrasound evaluation prior to 20 weeks gestation. The cohort was stratified according to pre pregnancy BMI $(<25.0$ or $\geq 25.0)$. The main outcome measure was knowledge regarding the risks of overweight and obesity in pregnancy.
\end{abstract}

Results: Over $75 \%$ of respondents identified that obese women have an increased risk of overall complications, including gestational diabetes and hypertensive disorders of pregnancy compared to women of normal weight. More than $60 \%$ of women asserted that obesity would increase the risk of caesarean section and less than half identified an increased risk of adverse neonatal outcomes. Women were less likely to know about neonatal complications (19.7\% did not know about the effect of obesity on these) than maternal complications (7.4\%). Knowledge was similar amongst women recruited at the public hospital and those recruited whilst attending for an ultrasound scan at a private clinic. For most areas they were also similar between women of lower and higher $\mathrm{BMI}$, but women with $\mathrm{BMI}<25.0$ were less likely to know that obesity was associated with increased rate of Caesarean section than those with higher BMI $(16.8 \%$ versus $4.5 \%, \mathrm{P}<0.001)$. Higher educational status was associated with more knowledge of the risks of overweight and obesity in pregnancy.

Conclusions: Many women correctly identify that overweight and obesity increases the overall risk of complications of pregnancy and childbirth. The increased risks of maternal complications associated with being obese are better known than the increased risk of neonatal complications. Maternal education status is a main determinant of the extent of knowledge and this should be considered when designing education campaigns.

\section{Background}

In line with the age and gender adjusted general population prevalence [1], approximately one third of pregnant women in Australia are overweight (BMI 25-29.9) or obese $(\mathrm{BMI}>30)[2,3]$. These rates are similar to the rates in other developed and developing countries [4]. Arguably, overweight and obesity are currently among the most common risk factors for adverse pregnancy outcomes [5]. Table 1 provides an overview of the

\footnotetext{
* Correspondence: I.callaway@uq.edu.au

${ }^{7}$ Centre for Diabetes and Endocrine Research, The University of Queensland, Bribane, Australia

Full list of author information is available at the end of the article
}

quoted prevalence and odds ratios for a number of pregnancy and neonatal complications for obese women compared to women of normal weight, derived from a detailed literature review in this area. These complications include gestational diabetes, hypertensive disorders, caesarean section, thromboembolism, perinatal infections and in the neonate high birth weight or macrosomia, higher rates of intensive care nursery admission, congenital anomalies, preterm delivery, stillbirth and perinatal death $[1,6-8,1,9-13,1,14-16$, $1,15,17-40]$. Obesity in pregnancy is therefore associated with greater direct costs of \$ 2387 (CI: \$1799-\$3109; $P$ $<0.0001)$ per pregnancy [41]. 
Table 1 Prevalence and odds ratios for pregnancy and birth complications

\begin{tabular}{|c|c|c|c|c|}
\hline $\begin{array}{l}\text { Pregnancy and Birth } \\
\text { Complications }\end{array}$ & $\begin{array}{l}\text { Prevalence in normal } \\
\text { weight women }\end{array}$ & $\begin{array}{l}\text { Prevalence in obese } \\
\text { women }\end{array}$ & $\begin{array}{l}\text { Range of Odds ratios } \\
\text {-obese women }\end{array}$ & $\begin{array}{l}\text { Range of Odds ratios -Class II } \\
\text { and or III obesity }\end{array}$ \\
\hline Gestational diabetes & $\begin{array}{l}1.2-4.1 \% \\
14,17,18,54\end{array}$ & $\begin{array}{l}3.5-9.5 \% \\
14,15,17,18,23,54\end{array}$ & $\begin{array}{l}2.6-5.2 \\
15,16,18,20,23,54\end{array}$ & $\begin{array}{l}4-7.4 \\
14, i 7,18\end{array}$ \\
\hline $\begin{array}{l}\text { Hypertensive disorders of } \\
\text { pregnancy }\end{array}$ & $\begin{array}{l}0.7-4.8 \% \\
14,17,18\end{array}$ & $\begin{array}{l}1.4-13.5 \% \\
14,15,17,18\end{array}$ & $\begin{array}{l}2.1-5.2 \\
13,14-16,18,20\end{array}$ & $\begin{array}{l}3.2-4.9 \\
10,14,17,18\end{array}$ \\
\hline Caesarean section & $\begin{array}{l}7.7-22.3 \% \\
10,14,17\end{array}$ & $\begin{array}{l}10.4-36.2 \% \\
14,15,17\end{array}$ & $\begin{array}{l}1.7-2.9 \\
15,16,17,20\end{array}$ & $\begin{array}{l}2.5-3.0 \\
14,16,17\end{array}$ \\
\hline $\begin{array}{l}\text { Premature birth }<37 \\
\text { weeks }\end{array}$ & $\begin{array}{l}5.4-19.6 \% \\
14,16,17,18\end{array}$ & $\begin{array}{l}6.4-30.7 \% \\
12,14,15,17,18\end{array}$ & $\begin{array}{l}0.9-1.6^{*} \\
15,18,20,38\end{array}$ & $\begin{array}{l}1.5-1.85 \\
17,18\end{array}$ \\
\hline $\begin{array}{l}\text { Special care nursery } \\
\text { admission }\end{array}$ & $\begin{array}{l}4.3-9.3 \% \\
17\end{array}$ & $\begin{array}{l}6-33.2 \% \\
17\end{array}$ & $\frac{1.2-1.3}{16}$ & $\frac{1.4-3.4}{16}$ \\
\hline Congenital abnormality & $\begin{array}{l}1.2-4.5 \% \\
16,22,23,36\end{array}$ & $\begin{array}{l}2.2-5.5 \% \\
22-24,29,31-33,36\end{array}$ & $\begin{array}{l}1.1-2.6^{*} \\
22-24,36\end{array}$ & $\begin{array}{l}1.4-3.4 \\
14,22,29\end{array}$ \\
\hline
\end{tabular}

The odds ratios represent a range of published unadjusted odds ratios, confidence intervals are not included. Class $\|$ obesity, BMI between 35.0 and $39.9 \mathrm{~kg} / \mathrm{m}^{2}$; Class III obesity, BMI $\geq 40.0 \mathrm{~kg} / \mathrm{m}^{2}$. * Published odds ratios have $95 \%$ confidence intervals crossing 1.0 , implying that the relationships are not statistically significant.

Increasing women's knowledge of the short and longterm risks of obesity to both their own and their offspring's health is likely to be an important first step in preventing obesity in pregnancy. Indeed recommendations to improve preconception care emphasize the need to ensure that women of childbearing age understand factors that increase the risks of childbearing, including obesity [42]. Our study was designed to ascertain whether or not women in the general pregnant population were aware of the increased risks associated with obesity in pregnancy. Furthermore, we investigated whether or not the pre pregnancy BMI was associated with differences in risk perception for complications in obese women.

\section{Methods}

We developed a questionnaire and surveyed 412 consecutive unselected women in early pregnancy as previously reported [43]. These women were either attending a public antenatal "first visit" clinic $(\mathrm{n}=255)$, or undergoing a routine private ultrasound evaluation prior to 20 weeks gestation $(n=157)$ [44]. $61.9 \%$ of study participants were cared for in the public sector, similar to previously published proportions from Queensland [45]. Pre pregnancy BMI was available for 368 women. Women completed the survey independently while waiting for appointments. A trained research midwife was present at all times, to assist if participants required clarification regarding any component of the survey. The response rate for the questions varied between 96 and 100\%. Permission for this study was obtained from the Royal Brisbane and Women's Hospital Health Research and Ethics Committee.

\section{Data collection}

Participants were asked to rate their perception of the risk of a pre-specified list of seven maternal and neonatal complications for women who were 'very underweight', 'normal weight' and 'very obese'. For each complication and with each weight status women were asked to indicate level of risk using a 5 point Likert scale (very low risk, low risk, average risk, high risk, very high risk, in addition to a "don't know" option). The specific questions used are shown in Additional file 1.

Participants were also asked "If a very obese woman was able to lose weight before pregnancy, how do you think this would affect her risk of pregnancy and birth complications?" The same seven factors were rated on a 5 point Likert scale using the following descriptors: She would be at much lower risk, She would be at lower risk, There would be no change in risk, She would be at higher risk, She would be at much higher risk (see Additional file 1).

\section{Definition of knowledge about the risks of being obese prior to pregnancy}

We assessed the way in which women rated risk for each complication for a normal and very obese woman. For the purposes of more detailed analysis, we evaluated women's broad knowledge about the risks of pregnancy and birth complications associated with being very obese. To be categorized as having broad knowledge about the risks of being very obese, women needed to rate the overall risk of complications as high or very high, and had to identify that weight loss prior to pregnancy is associated with a lower or much lower overall risk of complications.

\section{Factors associated with knowledge about the risks of being obese}

A number of demographic and obstetric history questions were included in the questionnaire. We explored the univariable and independent (of all other factors 
considered) associations of characteristics that we a priori thought were likely to be associated with knowledge and that might be useful in determining which groups of women should be specifically targeted to increase knowledge. The factors considered in these analyses were: maternal age (categorized as $<25$ years, 25-35 years, > 35 years), parity (categorized as nulliparous or multiparous), smoking during current pregnancy (yes versus no), personal income (categorized as $>40$ 000 or $\leq 40000$ AUD per year), obstetric care (classified as public or private), pregnancy planning (categorized as planned or unplanned), highest educational status (classified as < Year 12, completed Year 12 or completed a tertiary qualification), body mass index (BMI) prior to pregnancy derived from self-report of pre pregnancy weight and height (categorized as $<25 \mathrm{~kg} / \mathrm{m}^{2}$ or $\geq 25$ $\mathrm{kg} / \mathrm{m}^{2}$ ), periconceptual folate supplementation (yes versus no), attendance at a pre pregnancy planning visit with a doctor (yes versus no), weight loss attempts prior to current pregnancy (yes versus no), previous history of pregnancy-induced hypertension (yes versus no), of gestational diabetes (yes versus no) and of neonatal morbidity or mortality (including low birth weight baby, preterm baby, baby with a birth defect, death of baby within 1 month, baby requiring special or intensive care nursery).

\section{Statistical analysis}

Differences between women with a pre pregnancy BMI $<25.0$ or $\geq 25.0$ were analysed by two-sided $\mathrm{X}^{2}$ tests. $\mathrm{P}<$ 0.05 was considered statistically significant. Logistic regression was used to assess the relationship between each explanatory variable and "knowledge" of the risks of being very obese prior to pregnancy. Continuous variables (maternal age, BMI) were explored both as continuous and categorical variables, to ensure that this did not have an important effect on any of the multiple logistic regression models. Variables with several categories (parity, personal income) were explored using the original multiple categories and the dichotomized variable presented here in the results, to ensure that this did not substantially alter any of the odds ratios presented here. Multivariable logistic regression was used to further investigate some of the positive associations that we found. All analyses were performed with the statistical software package STATA v11.0.

\section{Results}

The baseline characteristics of the participating women are presented in Table 2. There was no difference in the baseline characteristics between women with a pre pregnancy BMI of $<25.0$ and those with $\geq 25.0$, except for BMI itself. Participants were asked to rate risk for a normal weight and a very obese woman for a variety of
Table 2 Participant demographic characteristics.

\begin{tabular}{lccc}
\hline & $\begin{array}{c}\text { BMI < } \\
\mathbf{2 5 . 0}\end{array}$ & $\begin{array}{c}\text { BMI } \mathbf{2} \\
\mathbf{2 5 . 0}\end{array}$ & P-value \\
\hline $\mathrm{N}$ & 257 & 111 & \\
Age & $31.6 \pm 4.9$ & $31.4 \pm 5.9$ & 0.75 \\
Nulliparous (\%) & 48.8 & 41.7 & 0.40 \\
Gestation (weeks) & $19.1 \pm 6.0$ & $20.0 \pm 6.6$ & 0.18 \\
Pregnancy planned (\%) & 65.3 & 66.1 & 0.88 \\
Prepregnancy health check (\%) & 47.5 & 43.5 & 0.47 \\
Periconception folic acid & 41.1 & 45.2 & 0.46 \\
supplements (\%) & & & \\
Tertiary degree (\%) & 61.5 & 62.6 & 0.84 \\
Public hospital patient (\%) & 57.0 & 67.0 & 0.07 \\
Born in Australia (\%) & 74.2 & 78.3 & 0.40 \\
Smoking (\%) & 21.1 & 20.0 & 0.80 \\
Prepregnancy BMl (kg/m ${ }^{2}$ ) & $21.1 \pm 2.2$ & $30.9 \pm 5.7$ & $<$ \\
& & & $\mathbf{0 . 0 0 0 1}$ \\
\hline
\end{tabular}

Students t-test was used to compare between the groups for continuous variables and $\mathrm{Chi}^{2}$ for categorical variables.

pregnancy and birth outcomes. These results are stratified by BMI $<25.0$ or $\geq 25.0$ and presented in Figure 1 and Additional file 2. There were no statistically significant differences in the responses from the women in the two BMI categories; all rated the risk for adverse pregnancy and birth outcomes higher for a very obese woman. In general, women were more confident of the effect of obesity on maternal than neonatal outcomes with $9.0-16.8 \%$ and $20.7-22.3 \%$ responding "Don't Know" in the BMI $<25.0$ and $4.5-13.6 \%$ and $14.5-19.2 \%$ in the $\mathrm{BMI} \geq 25.0$ group for the different maternal and neonatal outcomes respectively. A majority of women rated the risks for a very obese woman of overall complications (74.6\% vs. $71.6 \%)$, gestational diabetes ( $87.8 \%$ vs. $86.5 \%)$, blood pressure problems $(88.2 \%$ vs. $88.3 \%)$ or caesarean section (53.6\% vs. $50.7 \%$ ) as high to very high, whereas the risk of preterm delivery (62.8\% vs. $60.9 \%)$, admission to special nursery care (63.9\% vs. $59.1 \%)$ and congenital anomalies (58.0\% vs. $62.7 \%)$ were rated as average to high in the $\mathrm{BMI}<25.0$ vs. BMI $\geq 25.0$ groups respectively.

In Table 3 data is presented regarding how participants rated the risk of a very obese woman in comparison to a woman of normal weight, again stratified according to pre pregnancy BMI. The majority of the respondents were aware of the increased risk of overall complications, gestational diabetes and hypertensive disorders in obese women whereas a smaller proportion identified higher risks for caesarean section, adverse neonatal outcomes and especially congenital anomalies. There were no significant differences in the responses of women with a pre pregnancy BMI $<25.0$ compared to those with a BMI $\geq 25.0$.

The majority of respondents thought that weight loss prior to pregnancy would lower the risk of all pregnancy 


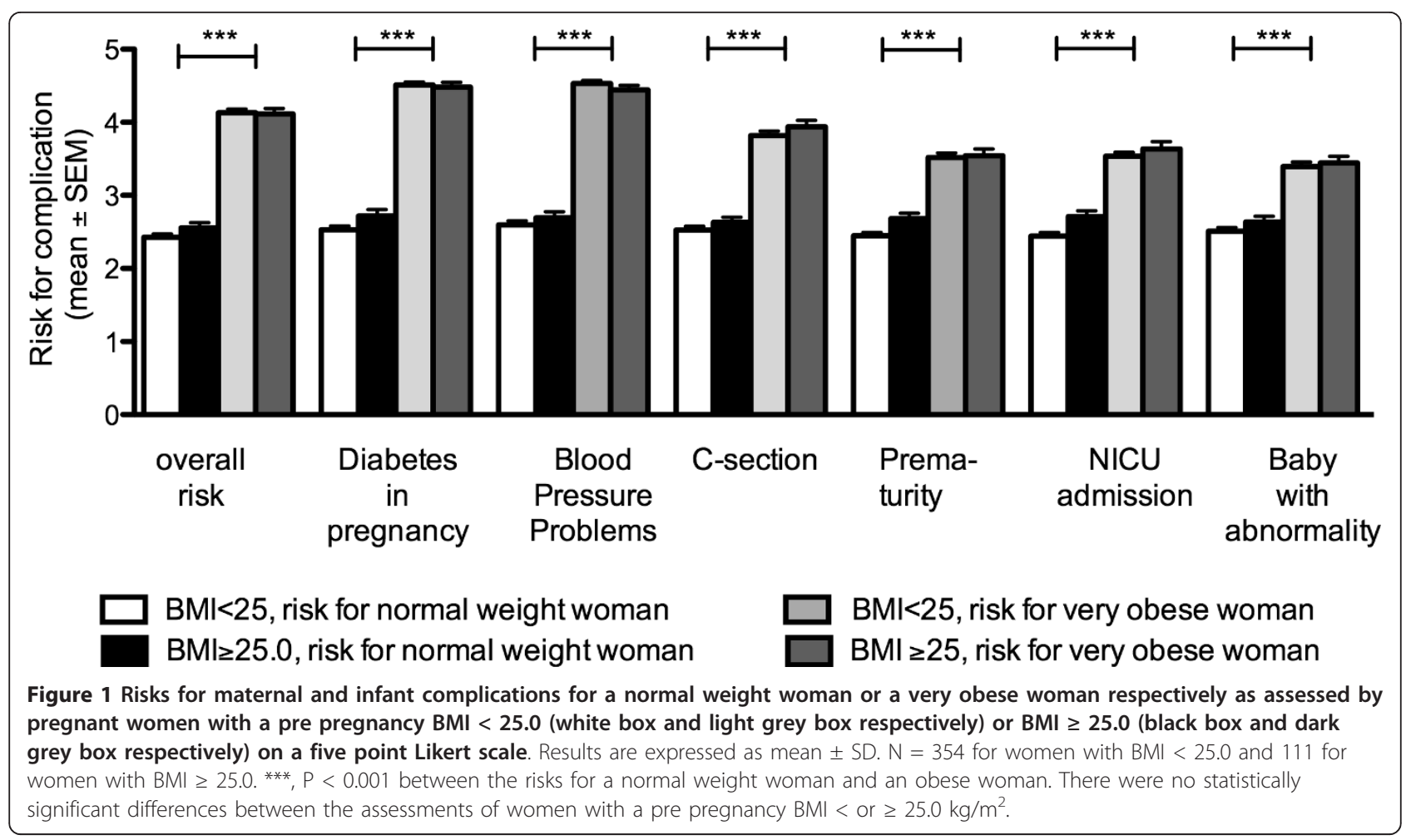

and birth complications independent of their own pre pregnancy BMI (Table 4).

Two hundred and thirty-five women (57\% of the total cohort independent of pre pregnancy BMI) were categorized as knowing about the risks of being obese on pregnancy, birth and neonatal outcomes. Table 5 provides information about a number of variables that we hypothesized might be related to knowledge about the risks of overweight and obesity. Educational status was consistently associated with knowledge of overweight and obesity prior to pregnancy. Women who were cared for in the private sector were more likely to be categorized as having a broad knowledge of the risks of overweight and obesity. These women were also more likely to have attended a preconception visit (98 of 157 women with private care $(62.4 \%)$ vs. 122 of 255 women with public care $(47.8 \%), \mathrm{P}<0.01)$. We adjusted this analysis for maternal educational status, and found that increased maternal educational status fully explained the difference in knowledge between women cared for in the private and public sector.

\section{Discussion}

$57 \%$ of the women in this study knew that being very obese prior to pregnancy increased the overall risk of pregnancy and birth complications, and that weight loss

Table 3 Participant rated risk of pregnancy and childbirth complications for women with a BMI $<25.0$ or $\geq 25.0$

\begin{tabular}{|c|c|c|c|c|c|c|c|c|}
\hline & \multicolumn{2}{|c|}{ Don't know (n(\%)) } & \multicolumn{2}{|c|}{$\begin{array}{l}\text { Very obese woman at } \\
\text { lower risk than normal } \\
\text { weight woman }(\mathrm{n}(\%))\end{array}$} & \multicolumn{2}{|c|}{$\begin{array}{l}\text { Very obese woman at the } \\
\text { same risk as normal } \\
\text { weight woman }(\mathrm{n}(\%))\end{array}$} & \multicolumn{2}{|c|}{$\begin{array}{l}\text { Very obese woman at } \\
\text { increased risk compared to } \\
\text { normal weigh woman }(\mathrm{n}(\%)\end{array}$} \\
\hline & $\mathrm{BMI}<25$ & $\mathrm{BMI} \geq 25$ & BMI < 25 & $\mathrm{BMI} \geq 25$ & BMI $<25$ & $\mathrm{BMI} \geq 25$ & BMI < 25 & $\mathrm{BMI} \geq 25$ \\
\hline Overall risk of complications & $27(10.6)$ & $14(12.8)$ & $1(0.4)$ & $0(0)$ & $23(9.1)$ & $112(11.0)$ & $203(79.9)$ & $83(76.2)$ \\
\hline Gestational diabetes & $28(11.1)$ & $12(10.9)$ & $1(0.4)$ & $0(0)$ & $13(5.2)$ & $11(10.0)$ & $210(83.3)$ & $87(79.1)$ \\
\hline Hypertension in pregnancy & $27(10.7)$ & $11(9.9)$ & $0(0)$ & $0(0)$ & $15(6.0)$ & $11(9.9)$ & $210(83.3)$ & $89(80.2)$ \\
\hline Caesarean section & $50(19.8)$ & $19(17.1)$ & $2(0.8)$ & $1(0.9)$ & $58(23.0)$ & $27(24.3)$ & $142(56.3)$ & $64(57.7)$ \\
\hline Prematurity & $57(22.5)$ & $19(17.3)$ & $5(2.0)$ & $4(3.6)$ & $63(24.9)$ & $44(40.0)^{* *}$ & $128(50.6)$ & $43(39.1)^{*}$ \\
\hline Special Care Nursery Admission & $55(21.8)$ & $20(18.2)$ & $0(0)$ & $4(3.6)$ & $77(30.4)$ & $40(36.4)$ & $121(47.8)$ & $46(41.8)$ \\
\hline Congenital abnormality & $62(24.6)$ & $23(20.9)$ & $1(0.4)$ & $2(1.8)$ & $93(36.9)$ & $44(40.0)$ & $96(38.1)$ & $41(37.3)$ \\
\hline
\end{tabular}

Total number of participants answering varies slightly ( $\mathrm{n}=252$ to 254 for women with $\mathrm{BMI}<25, \mathrm{n}=109$ to 111 for women with $\mathrm{BMI} \geq 25$ ). ${ }^{*} \mathrm{p}=0.04$ ${ }^{* *} \mathrm{p}=0.004$. All neonatal outcomes and C-section are rated as "dont' know"more frequently than maternal outcomes in both obese and non obese women $\mathrm{p}<$ 0.001 
Table 4 Responses regarding change in risk if an obese woman were to lose weight prior to pregnancy

\begin{tabular}{|c|c|c|c|c|c|c|}
\hline & \multicolumn{2}{|c|}{ Lower or much lower risk (n(\%)) } & \multicolumn{2}{|c|}{ No change in risk $(\mathrm{n}(\%))$} & \multicolumn{2}{|c|}{ Higher or much higher risk (n(\%)) } \\
\hline & $\mathrm{BMI}<25$ & $\mathrm{BMI} \geq 25$ & BMI $<25$ & $\mathrm{BMI} \geq 25$ & BMI $<25$ & $\mathrm{BMI} \geq 25$ \\
\hline Overall risk of complications & $197(80.4)$ & $83(77.6)$ & $19(7.8)$ & $13(12.1)$ & $29(11.8)$ & $11(10.3)$ \\
\hline Gestational diabetes & $191(78.3)$ & $78(72.9)$ & $24(9.8)$ & $17(15.9)$ & $29(11.9)$ & $12(11.2)$ \\
\hline Hypertension in pregnancy & $185(75.8)$ & $77(72.6)$ & $29(11.9)$ & $17(16.0)$ & $30(12.3)$ & $12(11.2)$ \\
\hline Caesarean section & $150(63.0)$ & $65(60.7)$ & $62(25.6)$ & $31(29.0)$ & $30(12.4)$ & $11(10.3)$ \\
\hline Prematurity & $146(60.3)$ & $54(55.7)$ & $67(27.7)$ & $34(35.1)$ & $29(12.0)$ & $9(9.3)$ \\
\hline Special Care Nursery Admission & $149(61.6)$ & $62(57.9)$ & $66(27.3)$ & $35(32.7)$ & $27(11.2)$ & $10(9.4)$ \\
\hline Congenital abnormality & $127(52.7)$ & $56(52.3)$ & $86(35.7)$ & $41(38.3)$ & $28(11.6)$ & $10(9.4)$ \\
\hline
\end{tabular}

The total number of participants answering each question varied from $n=241-245$ for women with BMI $<25.0$ and $n=97-107$ for women with BMI $\geq 25.0$

prior to pregnancy in an obese woman would reduce the overall risk of complications. The responses did not differ between normal weight and overweight or obese women.

The majority of women correctly identified the impact of overweight and obesity on maternal complications including diabetes and hypertensive disorders developing in pregnancy. The impact of pre pregnancy weight on caesarean section rates and neonatal outcomes was less well known (Figure 1 and Additional file 1). This is perhaps not surprising, given that relative risks are lower than for maternal adverse outcomes (Table 1). In addition, the increased risk of preterm delivery and congenital abnormalities is not consistently reported in the literature, until women are extremely obese (Class II and III obesity) although recent meta-analyses have indicated increased risks for both overweight and obese women $[38,40]$. Given that a healthy baby is a highly valued outcome of pregnancy [46], increasing women's knowledge about the impact on overweight and obesity on neonatal problems such as birth defects might encourage women to actively attempt to lose weight prior to pregnancy. A meta-analysis of Leventhal's common-sense models as a theoretical basis for intervention programs identified moderate to strong relationships between knowledge of disease, coping behaviors and outcomes [47]. Tailored diet and exercise interventions for at-risk individuals have been shown to be effective in improving outcomes in type 2 diabetes in a number of studies [48-50]. Therefore a program that will encompass an increase in knowledge of the risks of obesity for maternal and neonatal pregnancy outcomes with tailored easily implementable lifestyle interventions may improve pregnancy outcome for obese women.

Tertiary degree qualification was associated with knowledge about the risks of overweight and obesity. Maternal educational status also fully explained the difference we found in knowledge of the risks of being obese between women cared for in the private and public sectors and between women who did or did not smoke during pregnancy. Educational status is an important predictor of birth outcomes [51], and is associated with better knowledge of other preconception health issues such as periconceptual folate supplementation [5]. Our data would suggest that to improve knowledge regarding the risks of obesity, targeting public health messages at those with lower levels of education would be important.

This study identifies the pre pregnancy health check as an excellent opportunity for improving education of women regarding the risks of obesity prior to pregnancy. Slightly more than half of all women attended a doctor for a pre pregnancy health check. It is important that women have their BMI determined at their pre pregnancy health check, are advised about the risks associated with pre pregnancy overweight and obesity, and where appropriate are provided with support to lose weight [52]. However, this study also showed that education levels are associated with the level of knowledge and preconception visits to health care professionals, and efforts to increase knowledge about the risks associated with obesity during pregnancy in women with lower education levels should include additional measures besides information during preconception visits.

\section{Strengths and Limitations}

This study provides information on risk perception relating to the influence of being overweight and obese on pregnancy and birth complications in a relatively large unselected cohort of pregnant women cared for in the private and public sectors. Given the dearth of previous information in this area, we believe that our data will provide useful information to help develop public health interventions for reducing optimizing preconception weight mas well as providing a baseline against which to measure changes in knowledge after future interventions.

We were concerned that this cohort might have been particularly skewed towards well educated women. Women in our cohort had only slightly higher rates of tertiary education ( $34.9 \%$ vs. $28.8 \%$ ), and similar rates of secondary school non completion $(26.2 \%$ vs. $27.4 \%)$ in 
Table 5 Association between demographic variables and broad knowledge of obesity-related risk for pregnancy complications and outcomes.

\begin{tabular}{|c|c|c|c|c|c|}
\hline & \multirow[t]{2}{*}{ Total } & \multicolumn{2}{|c|}{ Broad know-ledge about absolute risks } & \multicolumn{2}{|c|}{ Unadjusted Analysis } \\
\hline & & $\mathrm{n}$ & $\%$ & OR & $95 \% \mathrm{Cl}$ \\
\hline \multicolumn{6}{|l|}{ Maternal Age } \\
\hline$<25$ & 46 & 21 & 45.6 & 1 & \\
\hline $25-35$ & 234 & 140 & 59.8 & 1.77 & $0.94,3.35$ \\
\hline$>35$ yrs & 132 & 73 & 55.3 & 1.47 & $0.75,2.89$ \\
\hline \multicolumn{6}{|l|}{ Educational status } \\
\hline Did not complete secondary school & 108 & 49 & 45.4 & 1 & \\
\hline Completed secondary school & 160 & 89 & 55.6 & 1.51 & $0.92,2.47$ \\
\hline Tertiary degree & 144 & 96 & 66.7 & 2.41 & $1.44,4.02$ \\
\hline \multicolumn{6}{|l|}{ Parity at birth } \\
\hline Nulliparous & 179 & 110 & 61.5 & 1 & \\
\hline Multiparous & 233 & 124 & 53.2 & 0.71 & $0.48,1.06$ \\
\hline \multicolumn{6}{|l|}{ Pregnancy planning } \\
\hline Unplanned & 82 & 75 & 51.4 & 1 & \\
\hline Planned & 266 & 159 & 59.8 & 1.19 & $0.97,1.45$ \\
\hline \multicolumn{6}{|l|}{ Obstetric care } \\
\hline Private & 155 & 100 & 63.7 & 1 & \\
\hline Public & 257 & 134 & 52.6 & 0.63 & $0.42,0.95$ \\
\hline \multicolumn{6}{|l|}{ Smoking status during pregnancy } \\
\hline Did not smoke in pregnancy & 321 & 188 & 58.6 & 1 & \\
\hline Smoked at all in pregnancy & 91 & 46 & 50.6 & 0.72 & $0.45,1.15$ \\
\hline \multicolumn{6}{|l|}{ Family Income } \\
\hline$>\$ 40000 / y r$ & 182 & 109 & 59.9 & 1 & \\
\hline$\leq \$ 40000 / y r$ & 190 & 112 & 58.9 & 0.96 & $0.63,1.45$ \\
\hline \multicolumn{6}{|l|}{ BMI Pre pregnancy } \\
\hline$<25$ & 265 & 160 & 60.4 & 1 & \\
\hline$\geq 25.0$ & 115 & 65 & 56.5 & 1.23 & $0.83,1.83$ \\
\hline \multicolumn{6}{|c|}{ Periconception folic acid supplementation } \\
\hline No & 180 & 97 & 53.9 & 1 & \\
\hline Yes & 232 & 139 & 59.1 & 0.96 & $0.65,1.42$ \\
\hline \multicolumn{6}{|l|}{ Pre Pregnancy Health Check } \\
\hline No & 192 & 110 & 57.3 & 1 & \\
\hline Yes & 220 & 124 & 56.4 & 0.85 & $0.55,1.33$ \\
\hline \multicolumn{6}{|c|}{ Weight loss attempts prior to pregnancy } \\
\hline No & 267 & 148 & 55.4 & 1 & \\
\hline Yes & 134 & 79 & 59 & 1.07 & $0.87,1.33$ \\
\hline \multicolumn{6}{|c|}{ Previous hypertensive disorders of pregnancy } \\
\hline No & 193 & 105 & 54.4 & 1 & \\
\hline Yes & 42 & 20 & 47.2 & 0.76 & $0.39,1.49$ \\
\hline \multicolumn{6}{|c|}{ Pre gestational or gestational diabetes } \\
\hline No & 185 & 222 & 57.5 & 1 & \\
\hline Yes & 48 & 12 & 46.1 & 0.63 & $0.28,1.40$ \\
\hline \multicolumn{6}{|c|}{ Previous neonatal morbidity or mortality } \\
\hline No & 386 & 97 & 52.4 & 1 & \\
\hline Yes & 26 & 27 & 56.2 & 1.17 & $0.61,2.21$ \\
\hline
\end{tabular}

comparison to national Australian data [1,17,20,53,54], hence this should not be a major source of bias in this study. It is possible that the responses in this survey might have been positively influenced by local media coverage regarding the problems of overweight and obesity which occurred at around the time of questionnaire administration and it would be useful to repeat this survey again in this population and also in other populations. 
It would be worthwhile to conduct a similar survey in health professionals, to assess their understanding of the risks associated with being overweight and obese prior to conception. A detailed knowledge in this group, of the adverse health consequences associated with elevated BMI on pregnancy would be associated with opportunities to address weight loss preconception. This would be especially amongst general practitioners, who generally would provide preconception check ups and could target women requiring weight loss prior to conception.

All the outcomes that we examined are associated with obesity. One of the limitations of this study is that we did not include a false outcome to test whether participants simply assumed all adverse outcomes would be more common in obese women (reflecting the relatively widespread portrayal as obesity as a major contributor to general ill-health). However, the relative risk of each outcome comparing obese to non-obese women does vary in the published literature (Table 1) and knowledge of the effect of obesity on outcomes with a lower relative risk was lower in this survey, indicating that the results may reflect real knowledge.

\section{Conclusions}

This study provides evidence that many women correctly identify that overweight and obesity increases the overall risk of complications of pregnancy and childbirth and that this was independent of the woman's own BMI. There remains scope for improvement in women's knowledge about obesity as a risk factor for pregnancy, birth and neonatal complications. Less well educated women are less likely to know about the risks of overweight and obesity in pregnancy, and so future public health campaigns need to ensure that these women are specifically considered.

\section{Additional material}

Additional file 1: Appendix 1. The appendix contains the list of questions posed to the participants in the survey regarding the knowledge of the effects of overweight and obesity in pregnancy.

Additional file 2: Participant response (\%) for risk of complications for women with $\mathrm{BMI}<$ and $\mathrm{BMI} \geq \mathbf{2 5}$. This file contains the tabular results for the data presented graphically in Figure 1.

\section{Acknowledgements}

This work was funded by a grant from the Royal Brisbane and Women's Hospital Foundation. The authors thank A/Prof Rob Cincotta and Dr Greg Duncombe for assisting with access to women who are cared for in the private sector.

\section{Author details}

${ }^{1}$ School of Medicine, Royal Brisbane Clinical School, The University of Queensland, Brisbane, Australia. ${ }^{2}$ Department of Internal Medicine Research
Unit, Royal Brisbane and Women's Hospital, Brisbane, Australia. ${ }^{3}$ Department of Maternity Services and Internal Medicine \& Aged Care, Royal Brisbane and Women's Hospital, Brisbane, Australia. ${ }^{4}$ Department of Social Medicine,

University of Bristol, Bristol, UK. ${ }^{5}$ Mater Children's Hospital, Brisbane, Australia. ${ }^{6}$ Departments of Endocrinology and Obstetric Medicine, Mater Health Services, Brisbane, Australia. ${ }^{7}$ Centre for Diabetes and Endocrine Research, The University of Queensland, Bribane, Australia. ${ }^{8}$ Department of Internal Medicine, Royal Brisbane and Women's Hospital, Brisbane, Australia.

\section{Authors' contributions}

MN performed data analysis and drafted the manuscript. KF/NF/KL performed data collection. DL/MC participated in data analysis. HM/LC conceived and designed the study, participated in data analysis and helped draft the manuscript. All authors have critically reviewed the manuscript and approved the final manuscript.

\section{Competing interests}

The authors declare that they have no competing interests.

Received: 9 September 2011 Accepted: 21 November 2011 Published: 21 November 2011

\section{References}

1. Callaway LK, Prins JB, Chang AM, Mclntyre HD: The prevalence and impact of overweight and obesity in an Australian obstetric population. Med J Aust 2006, 184(2):56-59.

2. Clinical guidelines on the identification, evaluation, and treatment of overweight and obesity in adults: executive summary. Expert Panel on the Identification, Evaluation, and Treatment of Overweight in Adults. Am J Clin Nutr 1998, 68(4):899-917.

3. McTigue KM, Harris R, Hemphill B, Lux L, Sutton S, Bunton AJ, Lohr KN: Screening and interventions for obesity in adults: summary of the evidence for the U.S. Preventive Services Task Force. Ann Intern Med 2003, 139(11):933-949.

4. Low S, Chin MC, Deurenberg-Yap M: Review on epidemic of obesity. Annals of the Academy of Medicine, Singapore 2009, 38(1):57-59.

5. Johnson K, Posner SF, Biermann J, Cordero JF, Atrash HK, Parker CS, Boulet S, Curtis MG: Recommendations to improve preconception health and health care-United States. A report of the CDC/ATSDR Preconception Care Work Group and the Select Panel on Preconception Care. MMWR Recomm Rep 2006, 55(RR-6):1-23.

6. Kaiser PS, Kirby RS: Obesity as a risk factor for cesarean in a low-risk population. Obstet Gynecol 2001, 97(1):39-43.

7. Young TK, Woodmansee B: Factors that are associated with cesarean delivery in a large private practice: the importance of prepregnancy body mass index and weight gain. Am J Obstet Gynecol 2002, 187(2):312-318, discussion 318-320.

8. Ehrenberg HM, Durnwald CP, Catalano P, Mercer BM: The influence of obesity and diabetes on the risk of cesarean delivery. Am J Obstet Gynecol 2004, 191(3):969-974.

9. Wolfe $\mathrm{H}$ : High prepregnancy body-mass index-a maternal-fetal risk factor. N Engl J Med 1998, 338(3):191-192.

10. Sibai BM, Gordon T, Thom E, Caritis SN, Klebanoff M, McNellis D, Paul RH: Risk factors for preeclampsia in healthy nulliparous women: a prospective multicenter study. The National Institute of Child Health and Human Development Network of Maternal-Fetal Medicine Units. Am J Obstet Gynecol 1995, 172(2 Pt 1):642-648.

11. Ness RB, Roberts JM: Heterogeneous causes constituting the single syndrome of preeclampsia: a hypothesis and its implications. Am J Obstet Gynecol 1996, 175(5):1365-1370.

12. Wolfe HM, Zador IE, Gross TL, Martier SS, Sokol RJ: The clinical utility of maternal body mass index in pregnancy. Am J Obstet Gynecol 1991, 164(5 Pt 1):1306-1310.

13. Stone JL, Lockwood CJ, Berkowitz GS, Alvarez M, Lapinski R, Berkowitz RL: Risk factors for severe preeclampsia. Obstet Gynecol 1994, 83(3):357-361.

14. Galtier-Dereure F, Boegner C, Bringer J: Obesity and pregnancy: complications and cost. Am J Clin Nutr 2000, 71(5 Suppl):1242S-1248S.

15. Cnattingius S, Bergstrom R, Lipworth L, Kramer MS: Prepregnancy weight and the risk of adverse pregnancy outcomes. N Engl J Med 1998, 338(3):147-152. 
16. Rosenberg TJ, Garbers S, Chavkin W, Chiasson MA: Prepregnancy weight and adverse perinatal outcomes in an ethnically diverse population. Obstet Gynecol 2003, 102(5 Pt 1):1022-1027.

17. Baeten JM, Bukusi EA, Lambe M: Pregnancy complications and outcomes among overweight and obese nulliparous women. Am J Public Health 2001, 91(3):436-440.

18. Weiss JL, Malone FD, Emig D, Ball RH, Nyberg DA, Comstock CH, Saade G, Eddleman K, Carter SM, Craigo SD, et al: Obesity, obstetric complications and cesarean delivery rate-a population-based screening study. Am J Obstet Gynecol 2004, 190(4):1091-1097.

19. Naeye RL: Maternal body weight and pregnancy outcome. Am J Clin Nutr 1990, 52(2):273-279.

20. Sebire NJ, Jolly M, Harris JP, Wadsworth J, Joffe M, Beard RW, Regan L, Robinson S: Maternal obesity and pregnancy outcome: a study of 287,213 pregnancies in London. Int J Obes Relat Metab Disord 2001, 25(8):1175-1182

21. Gross T, Sokol RJ, King KC: Obesity in pregnancy: risks and outcome. Obstet Gynecol 1980, 56(4):446-450.

22. Cedergren $M$, Kallen $B$ : Maternal obesity and the risk for orofacial clefts in the offspring. Cleft Palate Craniofac J 2005, 42(4):367-371.

23. Martinez-Frias ML, Frias JP, Bermejo E, Rodriguez-Pinilla E, Prieto L, Frias JL: Pre-gestational maternal body mass index predicts an increased risk of congenital malformations in infants of mothers with gestational diabetes. Diabet Med 2005, 22(6):775-781.

24. Ray JG, Wyatt PR, Vermeulen MJ, Meier C, Cole DE: Greater maternal weight and the ongoing risk of neural tube defects after folic acid flour fortification. Obstet Gynecol 2005, 105(2):261-265.

25. Anderson $J$, Waller DK, Canfield MA, Shaw GM, Watkins ML, Werler MM: Maternal obesity, gestational diabetes, and central nervous system birth defects. Epidemiology 2005, 16(1):87-92

26. Cedergren MI, Kallen BA: Maternal obesity and infant heart defects. Obes Res 2003, 11(9):1065-1071.

27. Watkins ML, Rasmussen SA, Honein MA, Botto LD, Moore CA: Maternal obesity and risk for birth defects. Pediatrics 2003, 111(5 Part 2):1152-1158.

28. Watkins ML, Botto LD: Maternal prepregnancy weight and congenital heart defects in offspring. Epidemiology 2001, 12(4):439-446.

29. Shaw GM, Todoroff K, Schaffer DM, Selvin S: Maternal height and prepregnancy body mass index as risk factors for selected congenital anomalies. Paediatr Perinat Epidemiol 2000, 14(3):234-239.

30. Shaw GM, Todoroff K, Finnell RH, Lammer EJ: Spina bifida phenotypes in infants or fetuses of obese mothers. Teratology 2000, 61(5):376-381.

31. Watkins ML, Scanlon KS, Mulinare J, Khoury MJ: Is maternal obesity a risk factor for anencephaly and spina bifida? Epidemiology 1996, 7(5):507-512

32. Shaw GM, Velie EM, Schaffer D: Risk of neural tube defect-affected pregnancies among obese women. Jama 1996, 275(14):1093-1096.

33. Werler MM, Louik C, Shapiro S, Mitchell AA: Prepregnant weight in relation to risk of neural tube defects. Jama 1996, 275(14):1089-1092.

34. Waller DK, Mills JL, Simpson JL, Cunningham GC, Conley MR, Lassman MR, Rhoads GG: Are obese women at higher risk for producing malformed offspring? Am J Obstet Gynecol 1994, 170(2):541-548.

35. Kallen K: Maternal smoking, body mass index, and neural tube defects. Am J Epidemiol 1998, 147(12):1103-1111.

36. Moore LL, Singer MR, Bradlee ML, Rothman KJ, Milunsky A: A prospective study of the risk of congenital defects associated with maternal obesity and diabetes mellitus. Epidemiology 2000, 11(6):689-694.

37. Feldman B, Yaron Y, Critchfield G, Leon J, O'Brien JE, Johnson MP, Evans MI: Distribution of neural tube defects as a function of maternal weight: no apparent correlation. Fetal Diagn Ther 1999, 14(3):185-189.

38. McDonald SD, Han Z, Mulla S, Beyene J: Overweight and obesity in mothers and risk of preterm birth and low birth weight infants: systematic review and meta-analyses. BMJ 341:c3428.

39. Cameron AJ, Welborn TA, Zimmet PZ, Dunstan DW, Owen N, Salmon J, Dalton M, Jolley D, Shaw JE: Overweight and obesity in Australia: the 1999-2000 Australian Diabetes, Obesity and Lifestyle Study (AusDiab). Med J Aust 2003, 178(9):427-432.

40. Stothard K, Tennant PW, Bell R, Rankin J: Maternal overweight and obesity and the risk of congenital anomalies: a systematic review and meta-analysis. JAMA 2009, 301(6):636-650.

41. Trasande L, Lee M, Liu Y, Weitzman M, Savitz D: Incremental charges, costs, and length of stay associated with obesity as a secondary diagnosis among pregnant women. Medical care 2009, 47(10):1046-1052
42. Australian Hospital Statistics, 2004-2005. Health Services Series Canberra: Australian Institute of Health and Welfare; 2006, 350.

43. Callaway LK, O'Callaghan MJ, Mclntyre HD: Barriers to addressing overweight and obesity before conception. Medical Journal of Australia 2009, 191(8):425-428.

44. Callaway LK, O'Callaghan MJ, Mclntyre HD: Barriers to addressing overweight and obesity before conception. Med J Aust 2009, 191(8):425-428.

45. Atrash HK, Johnson K, Adams MM, Cordero JF, Howse J: Preconception care for improving perinatal outcomes: the time to act. Matern Child Health J 2006, 10(Suppl 7):3-11.

46. Luo ZC, Wilkins R, Kramer MS: Effect of neighbourhood income and maternal education on birth outcomes: a population-based study. Cmaj 2006, 174(10):1415-1420.

47. Hagger MS, Orbell S: A Meta-Analytic Review of the Common-Sense Model of Illness Representations. Psychology \& Health 2003, 18(2):141-184.

48. Heideman WH, Nierkens V, Stronks K, Middelkoop BJ, Twisk JW, Verhoeff AP de Wit M, Snoek FJ: DiAlert: a lifestyle education programme aimed at people with a positive family history of type 2 diabetes and overweight, study protocol of a randomised controlled trial. BMC public health 2011, 11:751.

49. Mensink M, Blaak EE, Corpeleijn E, Saris WH, de Bruin TW, Feskens EJ: Lifestyle intervention according to general recommendations improves glucose tolerance. Obesity research 2003, 11(12):1588-1596.

50. Di Loreto C, Fanelli C, Lucidi P, Murdolo G, De Cicco A, Parlanti N, Santeusanio F, Brunetti $P$, De Feo P: Validation of a counseling strategy to promote the adoption and the maintenance of physical activity by type 2 diabetic subjects. Diabetes care 2003, 26(2):404-408.

51. de Jong-Van den Berg LT, Hernandez-Diaz S, Werler MM, Louik C, Mitchell AA: Trends and predictors of folic acid awareness and periconceptional use in pregnant women. Am J Obstet Gynecol 2005, 192(1):121-128.

52. Education and Training Experience, Australia, 2005 (Cat No 6278.0). Australian Bureau of Statistics; 2006.

53. Ehrenberg HM, Huston-Presley L, Catalano PM: The influence of obesity and gestational diabetes mellitus on accretion and the distribution of adipose tissue in pregnancy. Am J Obstet Gynecol 2003, 189(4):944-948.

54. Solomon CG, Willett WC, Carey VJ, Rich-Edwards J, Hunter DJ, Colditz GA, Stampfer MJ, Speizer FE, Spiegelman D, Manson JE: A prospective study of pregravid determinants of gestational diabetes mellitus. Jama 1997, 278(13):1078-1083.

\section{Pre-publication history}

The pre-publication history for this paper can be accessed here: http://www.biomedcentral.com/1471-2393/11/96/prepub

doi:10.1186/1471-2393-11-96

Cite this article as: Nitert et al:: Overweight and obesity knowledge prior to pregnancy: a survey study. BMC Pregnancy and Childbirth 2011 11:96.

\section{Submit your next manuscript to BioMed Central and take full advantage of:}

- Convenient online submission

- Thorough peer review

- No space constraints or color figure charges

- Immediate publication on acceptance

- Inclusion in PubMed, CAS, Scopus and Google Scholar

- Research which is freely available for redistribution 